improvement. These lie principally in educating and encouraging users to remember to enter appropriate and accurate key words and to check the completed record at each consultation, especially at the end of a period of care. Discussion of key word use at unit audit meetings and feedback to users have been shown to be of value. Further assessment will be necessary to see whether this effect is maintained.

In addition, and as a direct result of this study, we have started to modify the software to produce discharge summaries in a different way. Instead of consisting of free text dictated by a member of the medical staff it will now be generated automatically from the key word record in the database. The obligation to provide an accurate discharge summary will act as a stimulus to the medical staff to check that the record is complete and accurate. ${ }^{15}$

We thank Professor C S B Galasko, who had the original concept of the design of the Manchester orthopaedic database; Key Computers, which developed it; the consultants, junior medical staff, and secretaries at Ancoats Hospital; and the medical records staff for their help with collecting data for the study.
1 Ellis BW, Michie HR, Esufali ST, Pyper RJD, Dudley HAF. Development of a microcomputer-based system for surgical audit and patient administration: a review. F $R$ Soc Med 1987;80:157-61.

2 Dunn DC. Audit of a surgical firm by microcomputer: five years' experience. BMF 1988;296:687-91.

3 Brand DA, Krag MH, Hausman MR, Trainor KF, Akelman E, Rudicel SA et al. A patient registry for orthopaedic surgery. Clin Orhop 1990;252:262-9.

4 Kuslich SD, Peck CM. The human element in the design of computer assisted orthopaedic inpatient medical records systems. Orhop Clin North Am orthopaedic inparie

5 Lyons C, Gumpert R. Medical audit data: counting is not enough. $B M \mathcal{J}$

6 Marsh DR, Galasko CSB. The Manchester orthopaedic database. $\mathcal{F}$ Bone foin Surg [Br] 1990;72B:933.

7 Coleman NP, Warren PJ, Greenough CG. Accuracy and completeness of orthopaedic computer audit. $\mathcal{I} R$ Coll Surg $E$ dinb (in press).

8 Swansea Physicians' Audit Group. Audit of the quality of medical records in a district general medicine unit. F $R$ Coll Physicians Lond 1983;17:208-12.

9 Heath DA. Random review of hospital patient records. BMF 1990;300:651-2.

10 Whates PD, Birgzalis AR, Irvine M. Accuracy of hospital activity analysis codes. $B M \mathcal{F}$ 1982;284:1857-8.

11 Rees JL. Accuracy of hospital activity analysis data in estimating the incidence of proximal femoral fractures. $B M \mathcal{F} 1982 ; 284: 1856-7$.

12 Sunderland R. Inaccurate coding corrupts medical information. Arch Dis Child 1985;60:593-4.

13 Yates JM, Davidge MG. Can you measure performance? BMF 1984;288: $1935-6$

14 Kurtz D, Morrish KA. A microcomputer approach to storage of qualitative patient data using key words. Comput Biomed Res 1983;16:209-17.

15 Smith RP, Holzman GB. Application of a computer database system to generation of hospital discharge summaries. Obstet Gynecol 1989;73:803-7.

(Accepted 8 October 1991)

\title{
International Quality Assurance
}

\section{Quality assurance in Finland}

\author{
Hannu Vuori
}

\section{A failed head start}

Finland once tried to make a head start with quality assurance. While most of Europe was still slumbering like Sleeping Beauty, it flirted with quality assurance in the early 1970s. In 1971 the Finnish Hospital League urged all hospitals to start medical audit. Today, 20 years later, not a single hospital has heeded the advice. How did quality assurance start and why did it fail?

As the recommendation for starting medical audit resulted from my doctoral dissertation, ${ }^{1}$ I shall venture to look at its development from a personal point of view. It all started from an academic interest. When I came across quality assurance, at the University of California, Berkeley, during the mid-1960s I believed that the ideas must be applicable in Finland. Back in Finland I launched a study with two aims: to assess whether medical audit is possible in Finnish hospitals and whether assessors with different levels of medical knowledge (physicians, nurses, and lay people) use objective criteria to screen medical records for poor quality in the same way. The experience of the United States shows that quality assurance is a hot potato. I therefore carefully tried to avoid stepping on people's toes. My first choice was to focus on the methods of quality assurance, not on the actual quality of care delivered. My second choice concerned my coworkers. Working in a department of social medicine, I was an outsider; I knew that I could not gain the confidence of my clinical colleagues without involving them. I asked them to develop the criteria of good care. I also tried to consult the respective professors at every major step of the study.

The study reached its goals. But it also showed that my fears had been warranted. Though the younger clinicians were sympathetic and cooperative, the older clinicians, particularly the professors, tried to sink the study - and with it the spectre of quality assurance.

What went wrong? The study provided some probably universal lessons. Firstly, that because quality assurance is a practical venture to solve problems in patient care, an academic interest is not the best starting point. It does not convince the clinicians that quality assurance is useful; at best, they find it a nuisance, at worst a threat. Secondly, that outsiders, particularly those from other disciplines, are unwelcome intruders. It is not enough to inform and involve clinicians; they should do most of the work. The greatest mistake was perhaps the recommendation put forward by the Hospital League. As the league represents the hospital owners, the clinicians interpreted the move as a veiled hint that "big brother" would like to take control.

\section{Long detour}

Quality assurance only takes off if you can show a need for it. The Finnish clinicians were content with the situation. If they had heard of quality assurance, they found it relevant only for big countries, such as the United States, with many educational institutions and a great variety of treatment facilities. They accepted that under those circumstances the quality of care can vary and that systematic attempts to measure and improve it may be needed. Why should Finland need quality assurance? they asked. The country is small and has only a handful of medical schools that follow roughly the same curriculum. The care in hospitals and primary health care centres is consistently of high quality. The current societal and professional control mechanisms suffice to take care of the rare rotten apples.

Applied health research shattered this complacent view. In 1972 the Finnish Medical Research Council approved the country's first health research policy. Among the new priorities were epidemiology and health services research. The new generation of epidemiologists and health services researchers, trained with the support of the research council, became interested in small area variation. In study after study they showed variation in infant mortality among 
regions, in number of radiographs taken per patient with a given diagnosis among central hospitals, rates of wound infections among clinics and of decubitus among wards and variation within many other variables. The results raised a troubling question: Does variation reflect poor quality? The health authorities, clinicians, and researchers began to admit that it might. The response was an attempt to standardise care.

Guidelines and attempts to standardise have always been part of health care, as the sections on diagnostics and therapy in medical textbooks testify. One of the all time favourites in the fournal of the American Medical Association, as measured by the citation index, ${ }^{2}$ is an article by Steinbrocker $e t a l$ that defines the therapeutic criteria for rheumatoid arthritis which shows the need for, and acceptability of, guidelines. ${ }^{3}$ Though guidelines, protocols, and algorithms developed by one institution or one professional group for a specific problem (such as rheumatoid arthritis) are common, comprehensive guidelines covering several levels of care (from primary to tertiary care) and several provider groups (from occupational therapists, through nurses, to physicians) are rare. The model health care programmes developed in Sweden and Finland, particularly during the 1970 s, are perhaps the most ambitious step in this direction. ${ }^{5}$

A care programme is a documented set of guidelines on how to manage a patient with a given problem in the best possible manner with available resources. Ideally, it is an agreement that all the parties concerned, including health care providers, administrators, decision makers, and patients, have jointly developed, approved, and adapted to the local conditions. ${ }^{6}$ It specifies who should be responsible for the recommended actions at the different levels of the health care system, and it aims at improving the quality, effectiveness, and cost efficiency of care.

Sweden and Finland took a different approach to their care programmes. Sweden limited the role of the national level to selecting important problems for which care programmes were needed and setting up a task force to put together a scientifically valid database. Regional and local teams of health professionals developed the actual programmes. In Finland national teams comprising representatives of all professional levels and groups concerned did most of the work. Although local adaptation was a key idea, this centralised approach may have contributed to a lack of sense of local ownership of the programme.

In both countries experience showed that the development and marketing of the programmes were most likely to succeed when certain criteria were fulfilled (box).

Although thorough evaluations of the care programme are lacking, anecdotal evidence suggests that they reached their goals. Yet both in Finland and in Sweden the development has since stopped. The programmes are still popular as practice oriented

\section{Elements required for success of health care programmes}

- Everyone concerned at all levels of care in all institutions

- Motivated project leader who is an acknowledged expert

- Users of the programmes received good training

- Politicians supported the programmes

- Those developing and carrying out the programme had enough time and other resources

- The results were properly evaluated

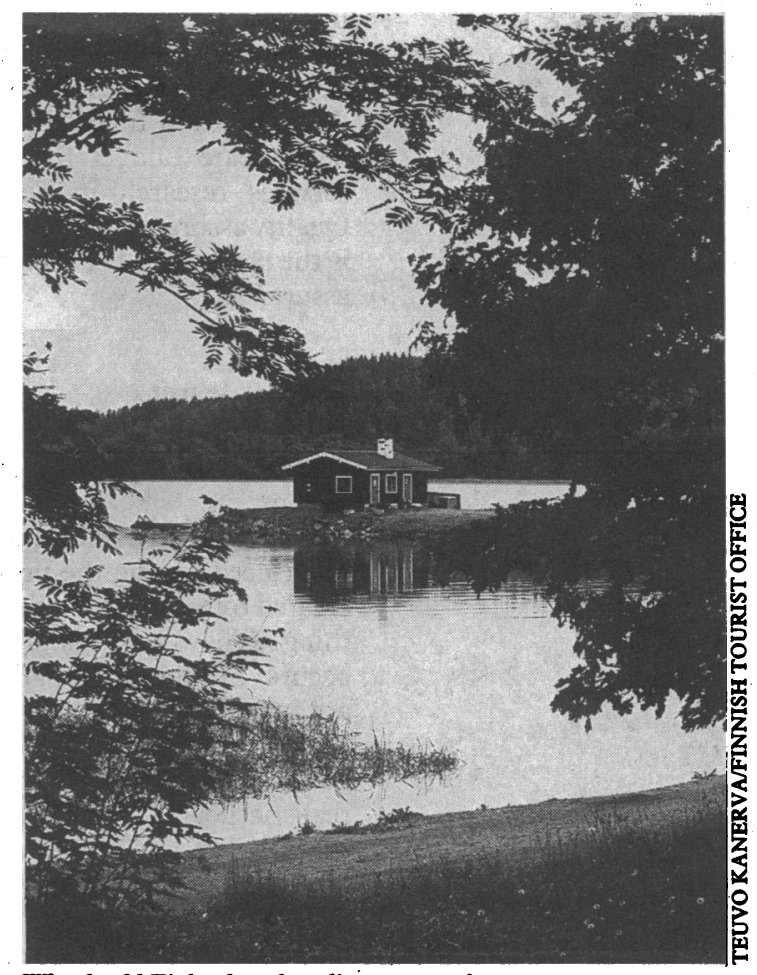

Why should Finland need quality assurance?

textbooks, but the health professionals do not use them to guide their daily work.

Although the programmes failed as tools to standardise care and improve its quality directly, they paved the way for quality assurance. Firstly, they put quality on the health policy agenda. Countless health care professionals participated in the development of the programmes, in the debate surrounding them, and in the training arranged to introduce them into health care during the 1970 s and early 1980 s. They learnt to accept the idea that special measures to improve quality of care are possible. Secondly, by describing what different health professionals should - and should not-do at the different levels of care, the programmes served as source of criteria for quality assurance. Thirdly, they emphasised that every health professional is responsible for the quality of care and that its improvement is a clinical activity.

\section{Second coming}

During the past five to six years quality assurance has been reborn. Just as in the history of quality assurance Florence Nightingale preceded E A Codman, Finnish nurses were there before Finnish doctors, having been influenced by the activities of the World Health Organisation..$^{78}$ In 1987 WHO organised an international training course in quality assurance in Finland, which helped to give respectability to quality assurance and to create a core group of devoted individuals, primarily nurses, with the basic skills. This group has since helped to launch research projects, write manuals, start nursing audit in many hospitals, and organise training courses. Gradually, other professional groups, for example, physiotherapists and occupational therapists, have picked up the challenge. Physicians have been much slower, but last year the National Board of Health (the highest health authority) and the Finnish Medical Association joined forces and organised the first seminar on quality assurance for leading doctors. Hospital regions have followed suit, although most participants have been nurses.

So far no hospital has an ongoing medical audit programme, but the conditions for launching programmes are good: studies have shown a need to 
improve the quality of care; training has increased awareness and interest; the national, regional, and hospital authorities support quality assurance; and there are even funds for it; a portion of the national health care budget has been earmarked for health services research in hospitals and health centres. Quality assurance is a priority area. The main handicap is the sharp split between nursing and medical quality assurance.

\section{Lessons learnt}

Though quality assurance in Finland is not yet a success story, the work so far has taught us several lessons.

Show a need-A sine qua non for quality assurance is a felt need among the providers of care. It cannot be created by telling them that quality assurance is a good thing. They need tangible proof that poor quality occurs. Studies on variations in the outcomes of care are an effective way to do it.

Small is beautiful, and nothing succeeds like success -A good strategy is to start from small projects with realistic goals. It is often better at first to choose a solvable but less important problem than a large and important one that may be too difficult to crack. Smal projects minimise the fear of losing face should they fail, and enlisting the support of key individuals is therefore easier.

Keep it professional and involve all those concerned Though the support of the administration may be essential for the success of a quality assurance project health professionals should carry it out. They should also work together. A great weakness in the current approach is the almost total separation of well established nursing audit and nascent medical audit. If appropriate for the goals of the project, then representatives of laboratory, radiology, and pharmacy departments and other support services and patients should be involved.

Reward rather than punish-Although quality assurance by definition looks for instances of poor care, the results of quality assurance studies should be made known in a non-putative way and instances of good care should be rewarded whenever possible.

Institutionalise and legislate late - Comprehensive and systematic quality assurance in all health care institutions may require a legal framework, but during the early phases it should be a voluntary activity carried out by health professionals.

The opinions expressed in this paper are the author's and do not necessarily reflect those of WHO.

1 Vuori $\mathrm{H}$. Terveydenhuollon ja sairaanhoidon laadun mittaaminen. Käsiteanalyyttinen ja metodinen tutkimus. Measurement of the quality of health care. A conceptual and methodological study [PhD dissertation]. Sairaalaliiton tutkimusosaston julkaisuja, Sarja F:1;Helsinki, 1970.

2 Garfield E. One hundred citation classics from the Journal of the American Medical Association. FAMA 1987;257:52-9.

3 Steinbrocker $\mathrm{O}$, Traeger $\mathrm{CH}$, Batterman RC. Therapeutic criteria in rheumatoid arthritis. FAMA 1949;140:659-62.

4 World Health Organisation. Principles of development of model health care programmes. Copenhagen: WHO, Regional Office for Europe, 1982.

5 Vuori $\mathbf{H}$. Scandinavian model health care programmes $-\mathbf{a}$ cousin of quality assurance. International foumal of Health Care Quality Assurance 1989;2:22-6. 6 Sjukvårdens Planerings-och Rationaliserings Institut. Swedish medical care programmes - for more efficient medical care. Stockholm: SPRI, 1985.

7 World Health Organisation. Nursing standards: towards better care - guidelines for standards of nursing practice. Copenhagen: WHO, Regional Office for Europe, 1984.

8 World Health Organisation. Principles of quality assurance. Copenhagen: WHO Regional Office for Europe, 1985

\section{Audit Views}

$\mathrm{M}$ issing case notes, incorrect coding, failure of doctors to agree on appropriateness of procedures, overelaborate studies, and generation of extra work were the chief causes of complaint at a conference on experiences of audit (Fournal of the Royal College of Physicians of London 1991;25:339-40). The message is keep it simple and do it at the time; a good example of this approach is the use of handheld computers by house physicians in Leeds to order tests.

Chould all patients aged over 60 be screened for hypothyroidism and if so how? A questionnaire about medical history and measurement of body mass index in over a thousand patients in a Birmingham general practice (British Fournal of General Practice 1991;41:414-6) failed to detect most of those found to have raised concentrations of thyroid stimulating hormone. Thus if screening is to be performed biochemical assays will be needed.

$\mathrm{E}$ rors in management - in diagnosis, decision making, and treatment-accounted for over half the 137 claims for negligence against obstetricians and gynaecologists, general surgeons, anaesthetists, and radiologists in New Jersey (Fournal of the American Medical Association 1991;266:2087-92). A further third were due to poor technical performance, and the remainder involved failures in staff communication and coordination. The authors suggest that study of such claims could prompt guidelines for safe practice, monitoring of procedures, and systems for sharing patient information among staff.

$\mathrm{S}$ hort term outcomes of hospital admission such as complications, length of stay, and use of resources can be accurately predicted by a standard assessment of severity of illness, functional capacity, and stability during the first 24 hours (Fournal of Clinical Epidemiology 1991;44: 1063-9). One year mortality of survivors is best predicted by estimates of functional capacity and a weighted measure of associated disease. neurysms and acute ischaemia were the main emer-

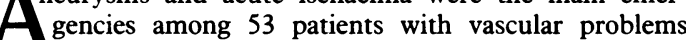
admitted during a three month period to a district hospital (British Fournal of Surgery 1991;78:1271-2). Most had to be dealt with by a single vascular surgeon; the workload was unpredictable and resulted in more out of hours, nonurgent operations and cancellation of planned admissions. The authors calculate that provision of one intensive therapy bed, five beds in the surgical wards, and a half day operating session a week would prevent the present disruption.

$\mathrm{H}$ ow do patients view digital and sigmoidoscopic recta examination? A simple questionnaire given to 103 patients found that most wished to be told how and why the investigation was to be performed (Postgraciuate Medical fournal 1991;67:904-6). Just over half felt that consent should be obtained and that a chaperone should be present, though the sex of the doctor performing the examination was not thought to be important. Over two thirds felt that sigmoidoscopy was no more uncomfortable than rectal examination.

A report from the research unit of the Royal College of Physicians (Fournal of the Royal College of Physicians of London 1991;25:325-8) highlights the needs not only of patient and family but of staff involved in palliative care. Clear guidelines are given for good practice, and, though admitting that outcome may be difficult to measure, the report provides a series of questions for auditing performance.

$\mathrm{H}$ istopathologists in Edinburgh have found that modifying the form they routinely fill in for each biopsy and cytology specimen provides a simple way of monitoring their work, adding "seconds only" to the reporting time for each specimen (Fournal of Clinical Pathology $1991 ; 44: 928-31)$. Monthly spot checks can then be done on workload (which was surprisingly constant); quality (over $90 \%$ of specimens were reported within 48 hours); and, more importantly, on deviations from acceptable standards. 